Article

\title{
Neutralization of Industrial Water by Electrodialysis
}

\author{
Oleksandr Petrov ${ }^{1, *}$, Natalia Iwaszczuk ${ }^{1}\left(\mathbb{D}\right.$, Tina Kharebava ${ }^{2}$, Irina Bejanidze ${ }^{2}$, Volodymyr Pohrebennyk ${ }^{3} \mathbb{D}$, \\ Nunu Nakashidze ${ }^{4}$ and Anton Petrov ${ }^{5}$
}

1 Faculty of Management, AGH University of Science and Technology, 30-059 Kraków, Poland; niwaszcz@zarz.agh.edu.pl

2 Department of Chemistry, Batumi Shota Rustaveli State University, Batumi, GE 6010, Georgia; tina.kharebava@bsu.edu.ge (T.K.); irina.bejanidze@bsu.edu.ge (I.B.)

3 Department of Ecological Safety and Nature Protection Activity, Lviv Polytechnic National University, 79013 Lviv, Ukraine; volodymyr.d.pohrebennyk@lpnu.ua

4 Department of Agroecology and Forestry, Batumi Shota Rustaveli State University, Batumi, GE 6010, Georgia; nunu.nakashidze@bsu.edu.ge

5 Department of Information Systems, Kuban State Agrarian University named after I.T. Trubilin, 350044 Krasnodar, Russia; petrov.a@kubsau.ru

* Correspondence: opietrov@zarz.agh.edu.pl; Tel.: +48-886-818-122

Citation: Petrov, O.; Iwaszczuk, N.; Kharebava, T.; Bejanidze, I.; Pohrebennyk, V.; Nakashidze, N.; Petrov, A. Neutralization of Industrial Water by Electrodialysis. Membranes 2021, 11, 101. https://doi.org/ 10.3390/membranes11020101

Academic Editor: Yoshihiko Sano

Received: 19 December 2020

Accepted: 27 January 2021

Published: 31 January 2021

Publisher's Note: MDPI stays neutral with regard to jurisdictional claims in published maps and institutional affiliations.

Copyright: (c) 2021 by the authors. Licensee MDPI, Basel, Switzerland. This article is an open access article distributed under the terms and conditions of the Creative Commons Attribution (CC BY) license (https:/ / creativecommons.org/licenses/by/ $4.0 /)$.

\begin{abstract}
The process of non-reagent adjustment of the $\mathrm{pH}$ of a $\mathrm{NaCl}$ solution $(0.5 \mathrm{~g} / \mathrm{L})$ of different acidity was investigated by the method of bipolar electrodialysis on a device operating according to the K-system (concentration). The experiments were carried out in the range $\mathrm{pH}=2.0-12.0$ with monopolar cation-exchange MK-40 (for alkaline solutions) or anion-exchange MA-40 (for acidic solutions) and bipolar MB-2 membranes. The regularities of the change in the $\mathrm{pH}$ of the solution on the current density, process productivity and energy consumption for the neutralization process have been investigated. Revealed: with different productivity of the apparatus $\left(\mathrm{Q}=0.5-1.5 \mathrm{~m}^{3 /} \mathrm{h}\right)$, in the range of $\mathrm{pH} 3.0-11.0$, with an increase in the current density, a neutral $\mathrm{pH}$ value is achieved. It has been shown that at $\mathrm{pH}$ above 11.0 and below 3.0, even at high current densities ( $\left.>20 \mathrm{~A} / \mathrm{m}^{2}\right)$, its value cannot be changed. This is due to the neutralization of the $\mathrm{H}^{+}$or $\mathrm{OH}^{-}$ions generated by the bipolar membrane by water ions, which are formed as a result of the dissociation of water molecules at the border of the monopolar membrane and the solution under conditions when the value of current exceeds the limiting value.
\end{abstract}

Keywords: electrodialysis; bipolar membrane; solution $\mathrm{pH}$ correction; water dissociation

\section{Introduction}

Environmental protection and rational use of natural resources are becoming increasingly important today to prevent pollution of water bodies with industrial wastewater. Wastewater containing mineral acids or alkalis is neutralized before being discharged into water bodies or before being used in technological processes. Neutralization is carried out in order to prevent corrosion of materials of sewage treatment facilities, disruption of biochemical processes in biological oxidants and in water bodies, as well as for precipitation of heavy metal salts from wastewater [1-3].

According to the degree of aggressiveness, industrial wastewater is divided into slightly aggressive (weakly acidic with $\mathrm{pH}=6.0-6.5$ and slightly alkaline with $\mathrm{pH}=8.0-9.0$ ), highly aggressive (strongly acidic with $\mathrm{pH}<6$ and strongly alkaline with $\mathrm{pH}>9$ ) and nonaggressive $(\mathrm{pH}=6.5-8.0)[4,5]$. When industrial wastewater is discharged into a reservoir or city sewer network, mixtures with $\mathrm{pH}=6.5-8.5$ are considered to be practically neutral. Considering the neutralizing ability of the reservoir and the alkaline reserve of urban wastewater, wastewater with a $\mathrm{pH}$ of less than 6.5 and more than 8.5 should be neutralized.

Neutralization can be carried out by various methods: mixing acidic and alkaline waste waters, adding reagents, filtering acidic waters through neutralizing materials, 
absorption of acid gases in alkaline waters, or absorption of ammonia in acidic waters [6,7] Precipitation may form during neutralization. Various reagents are used in the chemical treatment of industrial wastewater. To neutralize acidic waters, the following can be used: $\mathrm{NaOH}, \mathrm{KOH}, \mathrm{Na}_{2} \mathrm{CO}_{3}$, ammonia water, $\mathrm{CaCO}$, and $\mathrm{MgCO}_{3}$, and for alkaline waters-various acids or acid gases, for example, waste gases containing $\mathrm{CO}_{2}, \mathrm{SO}_{2}, \mathrm{NO}_{2}$, $\mathrm{N}_{2} \mathrm{O}_{3}$, etc. [8-11].

In many industrial and agricultural processes (washing water treatment, industrial wastewater treatment, caustic soda preparation, chlorine production, whey processing, and water preparation for use in agriculture and water supply systems), liquid treatment systems need to be developed to regulate $\mathrm{pH}$ [12-15].

When adjusting the $\mathrm{pH}$ of liquids with chemical reagents [16] and when preparing water for clarification, acidity is controlled by dosing alkaline or acid solutions. In control systems for growing plants under cover, an automatic measuring device of alkali and acid solutions with a concentration of $20-30 \%$ is also proposed. Despite the variety of methods for dosing chemical reagents, their use, as a rule, leads to great inconvenience in work for the following reasons:

$\checkmark \quad$ the formation of a large amount of sediments as a result of changes in acidity;

$\checkmark$ disruption of dosing mechanism operation due to clogging of holes;

$\checkmark$ the need to prepare reagent solutions of a certain concentration;

$\checkmark \quad$ inaccuracy in predicting and obtaining acidity values.

In addition, increasing the scale of production consumption requires additional reagent costs and, accordingly, increases the cost of water treatment. In addition, waters with $\mathrm{pH} \sim 7$, in case of their increased salinity of large water volumes, pose an environmental threat [17-19].

Membrane wastewater treatment methods are an alternative to reagent $\mathrm{pH}$ control systems. Membrane technologies belong to the category of resource-saving technologies, the use of which makes it possible to improve the quality of discharged wastewater, reduce the quantitative discharge of pollutants into water bodies, and minimize the intake of natural water due to the possibility of reusing treated wastewater in closed water supply systems [20-22].

According to the forecasts of the development of the world economy, membrane technology is regarded as the technology of the future [23-25]. It has been widely used in many industries and agriculture. Membrane processes are used in almost all spheres of human activity, since they ensure high efficiency of processes, namely: reduce the cost of materials, raw materials and energy; increase the thermal and energy potential; provide the population with drinking water; protect the environment, etc. [26-29]. Electrodialysis is one of the methods of membrane technology for the separation and purification of liquids [30-32]. Electrodialysis is an environmentally friendly [33]. The application of this method allows you to successfully carry out the processes of desalination and concentration of solutions, obtaining drinking water from salt water, treatment of natural and industrial wastewaters, etc. It is widely introduced in the energy, electronic, chemical, and food industries, and in medicine, agriculture and other spheres of human activities $[34,35]$. The world market of membrane technologies already occupies a significant segment of the world economy. According to experts' forecasts, the world demand for membranes will grow steadily. The annual volume of global sales of membranes and membrane equipment has recently increased by $10-12 \%$ and by the beginning of the XXI century amounted to over 11 billion US dollars.

The basis of electrodialysis is the selective transport of ions of a dissolved substance through ion-exchange membranes under the influence of an electric field. The driving force of this process is the gradient of the electric potential on both sides of the membrane. The scope of the electrodialysis method expanded with the use of bipolar membranes. A bipolar membrane is a two-layer composite membrane consisting of layers of cation- and anion-exchange membranes that are directly in contact with each other [36]. 
When the bipolar membrane is located with the cation-exchange side to the cathode and the anion-exchange one to the anode, the membrane generates $\mathrm{H}^{+}$and $\mathrm{OH}^{-}$ions due to the splitting of water molecules, even with a small electric field voltage at the interface between the layers [36] (Figures 1 and 2).

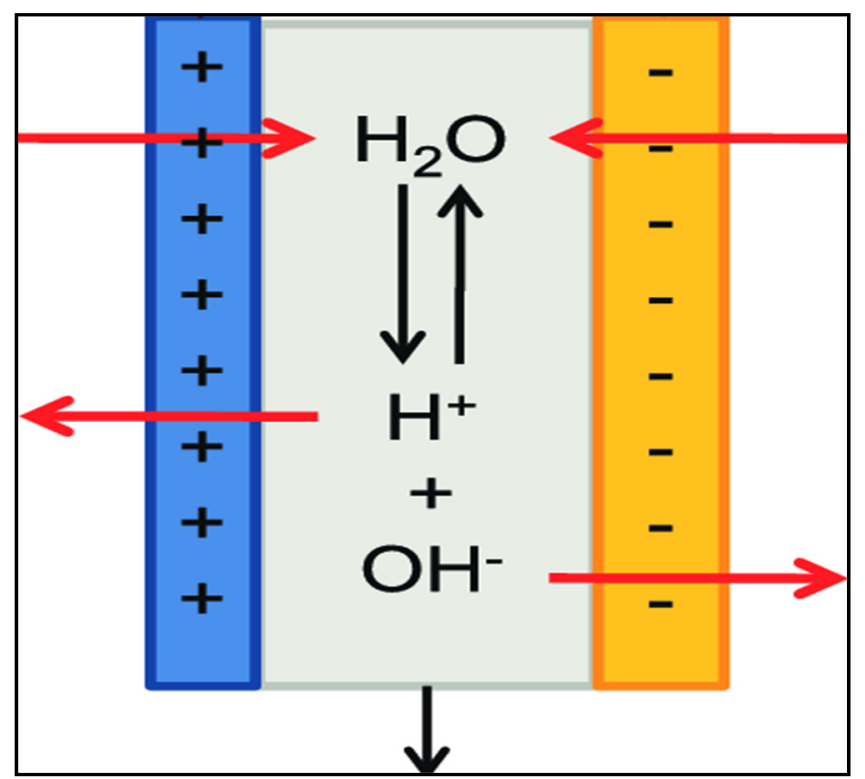

Figure 1. Generation of $\mathrm{H}^{+}$and $\mathrm{OH}^{-}$ions by the bipolar membrane.

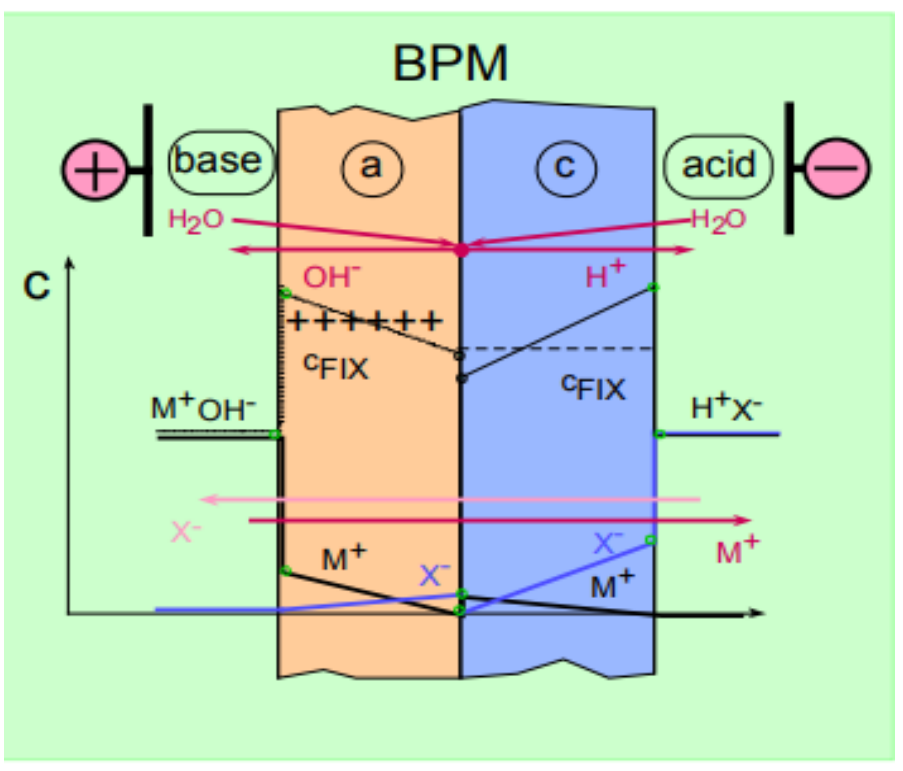

Figure 2. Schematic concentration profiles in a bipolar membrane.

This ability of the bipolar membrane is successfully used to obtain acids and bases from salt solutions or to carry out other chemical transformations involving hydrogen and hydroxyl ions. The decomposition of water in such systems is a "working" process and the efficiency of the applied electromembrane technology depends on the overvoltage and current efficiency with which the $\mathrm{H}^{+}$and $\mathrm{OH}^{-}$ions are generated.

Currently, electrodialysis with bipolar membranes is used not only to obtain acids and bases, but also for reagent-free regulation of the $\mathrm{pH}$ of various liquids $[35,36]$.

It is known that when growing plants on artificial substrates, it is necessary to regularly monitor the $\mathrm{pH}$ value. For most plants, the acidity of the medium is optimal, pH 5.5-6.5. 
The authors of [37] successfully solved the problem of controlling the acidity of hydroponic solutions by the method of bipolar electrodialysis. This method, in contrast to the chemical method, allowed them to obtain stable indicators of the acidity of the solution without changing the organoleptic properties.

Many scientists and engineers have attempted to develop fluid treatment systems in industrial and agricultural processes to control $\mathrm{pH}$ (preparation of washing water, treatment of industrial effluents, processes for producing caustic soda and chlorine, treatment of milk whey, and preparation of water for use in agriculture and water supply systems).

Enterprises, consumers of large amounts of water, have certain requirements for water. For example, the efficiency of the coagulation process in water treatment systems is largely dependent on the $\mathrm{pH}$ of water under treatment, since only at the optimum $\mathrm{pH}=10.0-10.5$, the minimum solubility and maximum strength of the resulting hydroxides is achieved. Also, washing wastewater, obtained after acid-base regeneration of ion-exchangers and those used in thermal and nuclear energy, before being discharged into the sewer, requires adjusting the acidity to a neutral media [38].

However, it should be noted that for each specific case of using the electrodialysis process, depending on the goal, it is necessary to select the type of electrodialysis apparatus and membranes, the hydraulic circuit, and electrical parameters of the process [39-42].

Thus, the issue of adjusting the $\mathrm{pH}$ of saline solutions and industrial effluents, without the use of chemical reagents, is very relevant, since it will simplify the technological schemes in use, reduce the volume of effluents and the cost of chemical reagents, and also concentrating and returning valuable products to the technological cycle will make the process more economical and, accordingly, reduce the risk of environmental pollution.

The purpose of this work: to study the process of reagent-free $\mathrm{pH}$ adjustment (up to neutral) of saline solutions of various acidities in a multi-chamber pilot plant operating according to the $\mathrm{K}$ (concentration) system, using the bipolar electrodialysis method, in order to reduce the aggressiveness of industrial effluents before being discharged into the sewer or to return the process products to the technological cycle production

The novelty of the work: Most of the work on adjusting the $\mathrm{pH}$ of solutions was carried out on model installations of small volume, consisting of a maximum of five to seven working chambers, using bipolar and anion-exchange membranes. In this work, the $\mathrm{pH}$ adjustment of solutions was carried out by the method of electrodialysis with bi- and monopolar ion-exchange membranes, on an experimental setup with 50 working chambers operating according to the K-concentration system. Through this system, the working solution was not supplied to the concentration chambers; a solution was formed in these chambers due to the generation of $\mathrm{OH}$ ions and hydrated sodium ions by the bipolar membrane, transferred through the cation exchange membrane, that is, alkali is formed in the concentration chambers. When an anion-exchange membrane is used in the concentration chambers, acid is formed due to the generation of $\mathrm{H}^{+}$ions and hydrated chlorine ions by the bipolar membrane. In parallel, the electroosmotic transfer of water to the concentration chambers takes place.

\section{Methods and Materials}

Investigation into the change in $\mathrm{pH}$ of salt solutions of different acidity was carried out on an experimental electrodialysis apparatus, consisting of two platinized titanium electrodes and a membrane package located between them which, when adjusting the $\mathrm{pH}$ of alkaline salt solutions, consisted of alternately arranged cation-exchange MK-40 and bipolar MB-2 membranes (Figure 3a), and in the case of acidic solutions-anion-exchange MA-40 and bipolar MB-2 membranes (Figure 3b). 


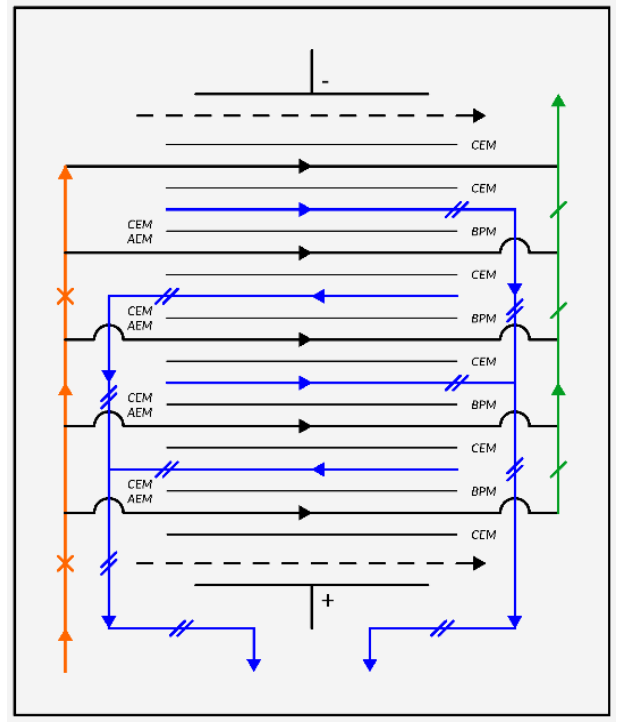

(a)

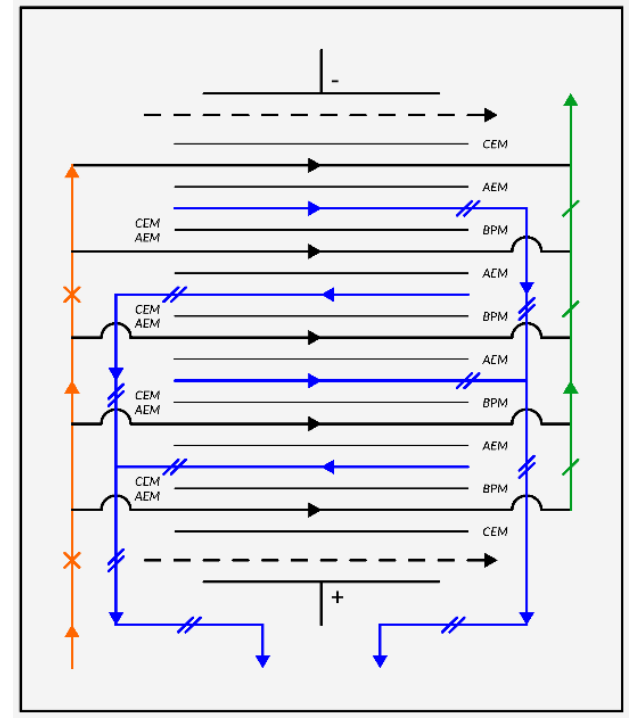

(b)

Figure 3. Schematic diagram of the electrodialysis process for the correction of acidic (a) and alkaline (b) solutions: AEM-anion, CEM-cation, and bipolar membrane (BPM); - $\mathrm{x}-$ - initial solution, - / - product and - // - concentrate.

The membranes are manufactured at JSC Shchekinoazot (Shchekino, Russia). The MK40 (Figure 4) cation-exchange membrane was made of the KU-2-8 strongly acidic cation exchanger composition containing sulfo groups and polyethylene; the MA-40 (Figure 5) anion-exchange membrane was made of the EDE-10 $\mathrm{P}$ anion exchanger composition containing quaternary ammonium bases $(20 \%)$, secondary amines and polyethylene. The bipolar membrane of the MB-2 brand is made on the basis of KU-2 gel-type sulfocationionite and $\mathrm{AB}-1$ gel-type benzyltrimethylammonium anionite containing the groups: $-\mathrm{SO}_{3} \mathrm{H},-$ $\mathrm{N}\left(\mathrm{CH}_{3}\right)_{2}$.

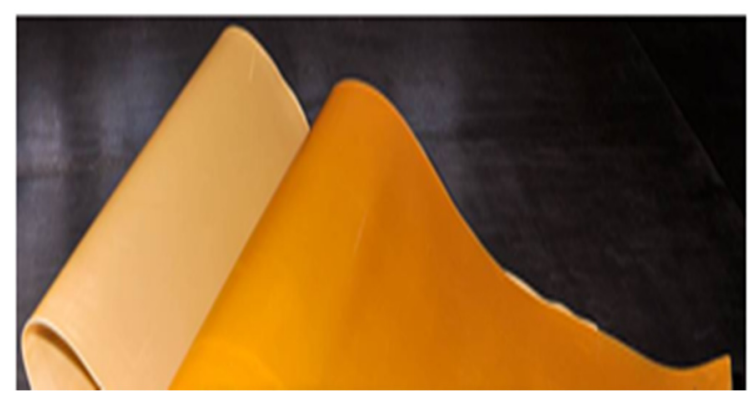

Figure 4. Cation-exchange MK-40.

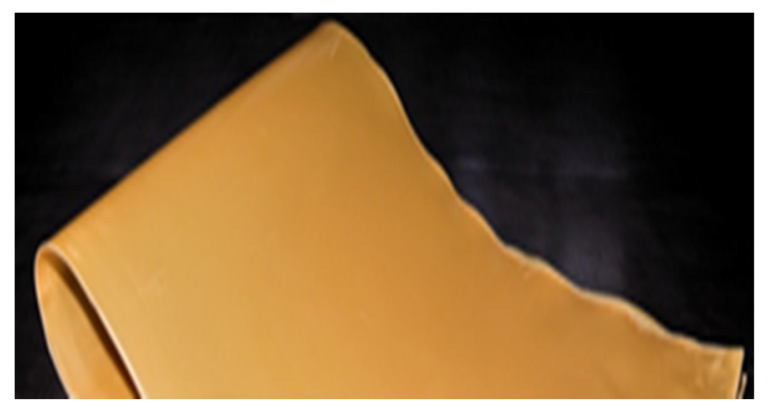

Figure 5. Bipolar MB-2 membrane anion-exchange membrane.

The scheme of the process for adjusting the $\mathrm{pH}$ of technological solutions is shown in Figure 6. 


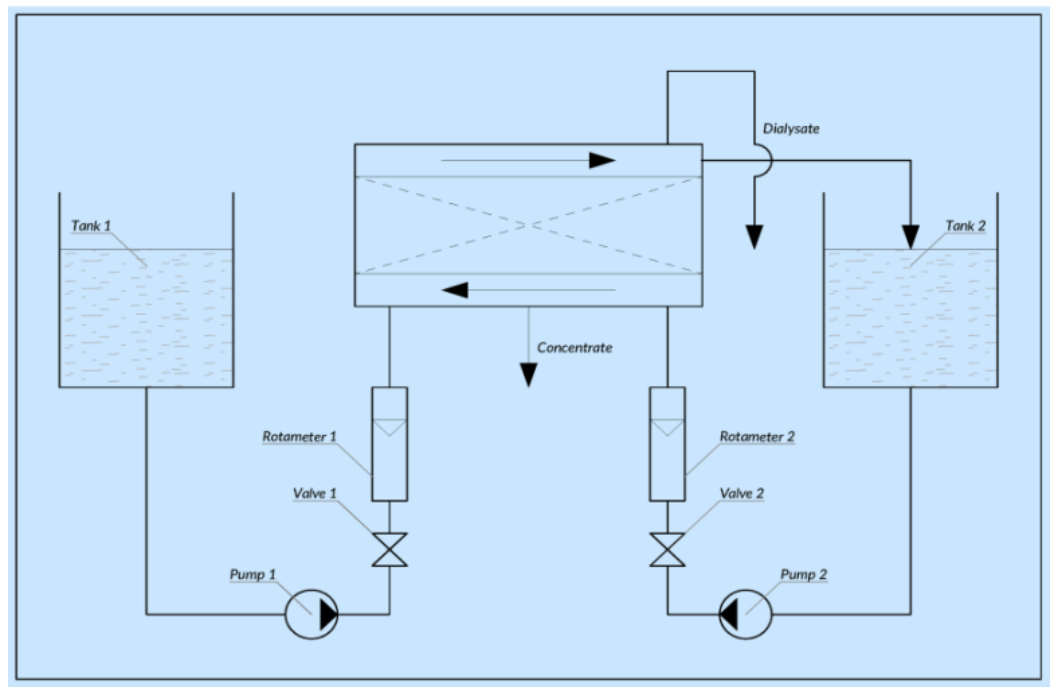

Figure 6. Scheme of the process for adjusting the $\mathrm{pH}$ of technological solutions.

The working solutions with different $\mathrm{pH}$ values were prepared by adding sodium chloride $(0.5 \mathrm{~g} / \mathrm{L})$, sodium hydroxide or hydrochloric acid solutions to the solution. The $\mathrm{pH}$ of the initial solutions varied in the range of $\mathrm{pH}=2.0-12.0$.

In this work, the $\mathrm{pH}$ adjustment of solutions were carried out in an experimental setup with 50 working chambers operating according to the K-concentration system. Through this system, the working solution was not supplied to the concentration chambers; a solution was formed in these chambers due to the generation of $\mathrm{OH}^{-}$ions and hydrated sodium ions by the bipolar membrane, transferred through the cation exchange membrane, that is, alkali is formed in the concentration chambers. When an anion-exchange membrane is used in the concentration chambers, acid is formed due to the generation of $\mathrm{H}^{+}$ions and hydrated chlorine ions by the bipolar membrane. In parallel, the electroosmotic transfer of water to the concentration chambers takes place.

The thickness of each chamber is $1.2 \mathrm{~mm}$, and the effective working area of one membrane is $0.124 \mathrm{~m}^{2}$. The membrane package was hydraulically assembled in parallel, which provides the same process conditions in all chambers. The initial solution was not supplied to the concentration chambers. The movement of fluid in these chambers was carried out due to the electroosmotic transfer of the solvent from the dialysate chamber.

The $\mathrm{NaCl}$ concentration was determined by the $\mathrm{Cl}^{-}$ion recalculated to $\mathrm{NaCl}$. The $\mathrm{Cl}^{-}$ ion content was determined by the argentometric method in the presence of the $\mathrm{K}_{2} \mathrm{CrO}_{4}$ indicator. The concentration of alkali and acid was determined by acid-base titration in the presence of the phenolphthalein indicator.

Experiments on adjusting the $\mathrm{pH}$ of the initial solutions of different acidity were carried out at a constant voltage on the apparatus and a constant flow rate of the initial solution into the dialysate chambers (flow rate $\mathrm{Q}=0.5-1.5 \mathrm{~m}^{3} / \mathrm{h}$ ). The process of electrodialysis correction of the acidity of each initial solution was carried out until the neutral medium of the solution was reached in the dialysate chamber, which was achieved with an increase in the voltage on the apparatus. The voltage value was controlled with a voltmeter, the current in the apparatus with an ammeter, and the consumption of the initial solution into the dialysate chambers with a rotameter.

For each hydraulic mode, by changing the value of the applied voltage to the apparatus, the optimal electrical parameters of the process were set and the following process indicators were calculated on their basis: operating capacity $(\mathrm{Q})$ and energy consumption (W) per process. These indicators were calculated using the formulas:

1. Process performance: 


$$
Q=\frac{V(\text { product })}{\tau \cdot S} l /\left(\mathrm{h} \cdot \mathrm{m}^{3}\right)
$$

where:

$\checkmark \quad V$ (product)—product volume, 1 ;

$\checkmark \quad \tau$-time, $\mathrm{h}$;

$\checkmark \quad S$-membrane area, $\mathrm{m}^{2}$

2. Energy consumption:

$$
\mathrm{W}=\frac{U \cdot I \cdot \tau}{V} \mathrm{~kW} \cdot \mathrm{h} / \mathrm{m}^{3}
$$

where:

$\checkmark \quad I$-amperage, $\mathrm{kW}$;

$\checkmark \quad \tau$-time, h;

$\checkmark \quad V$-product volume, $\mathrm{m}^{3}$;

$\checkmark \quad U$-voltage across the electrodialyzer

\section{Results and Discussion}

Reagentless acidity adjustment of saline solutions with initial $\mathrm{pH}=2.0-12.0$ was studied depending on the applied voltage to the apparatus. When alkaline salt solutions were passed through an electrodialysis apparatus, the $\mathrm{pH}$ of the solutions in the dialysate chambers decreased in accordance with the increase in voltage, almost to a neutral value. The alkaline working solutions are neutralized with hydrochloric acid formed in the dialysate tract by chlorine ions of the working solution and hydrogen ions migrated from the cationic layer of the bipolar membrane. At the same time, alkali is formed in the concentration chambers by sodium ions of the working solution and hydroxyl ions migrated from the anion layer of the bipolar membrane.

The process of adjusting the $\mathrm{pH}$ of solutions was studied at different operating capacities $\left(\mathrm{Q}=0.5-1.5 \mathrm{~m}^{3} / \mathrm{h}\right)$ of the apparatus. The results obtained during the experiment are shown in Figures 7-11.

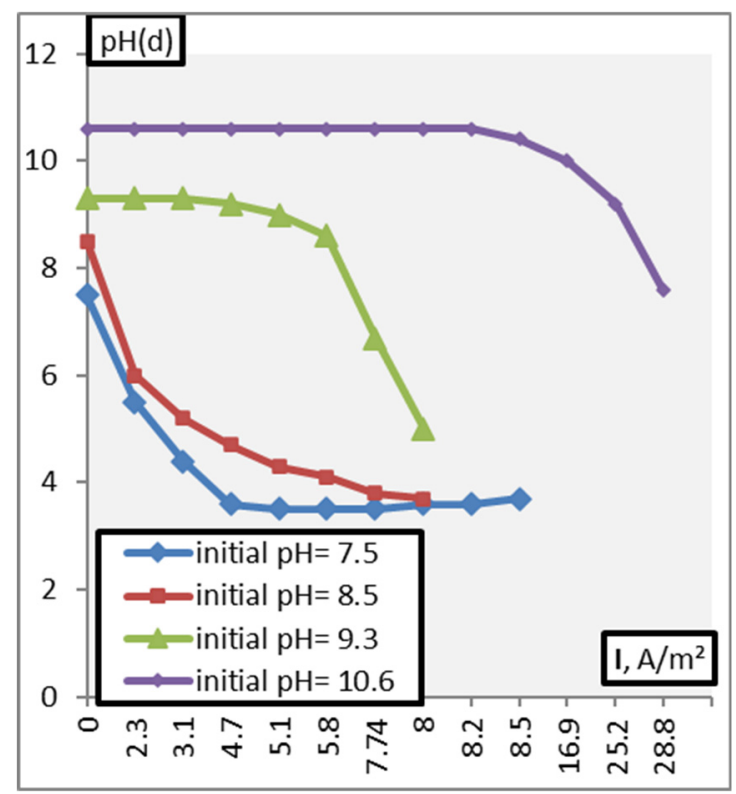

(a)

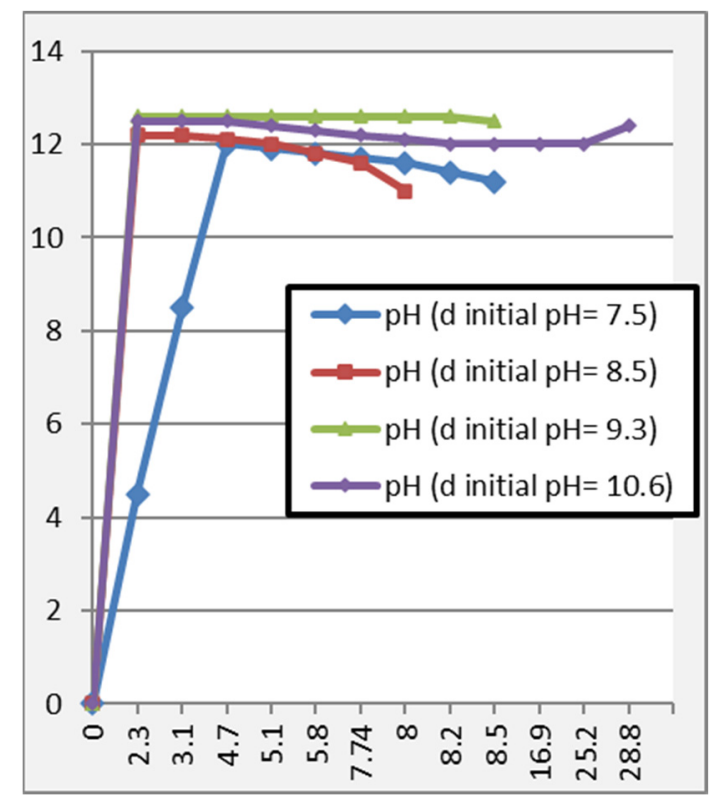

(b)

Figure 7. Dependence of the $\mathrm{pH} .(\mathbf{a})-\mathrm{pH}(\mathrm{d}),(\mathbf{b})-\mathrm{pH}(\mathrm{c}))$ adjustment of alkaline solutions on the current density (ddialysate, c-concentrate). 


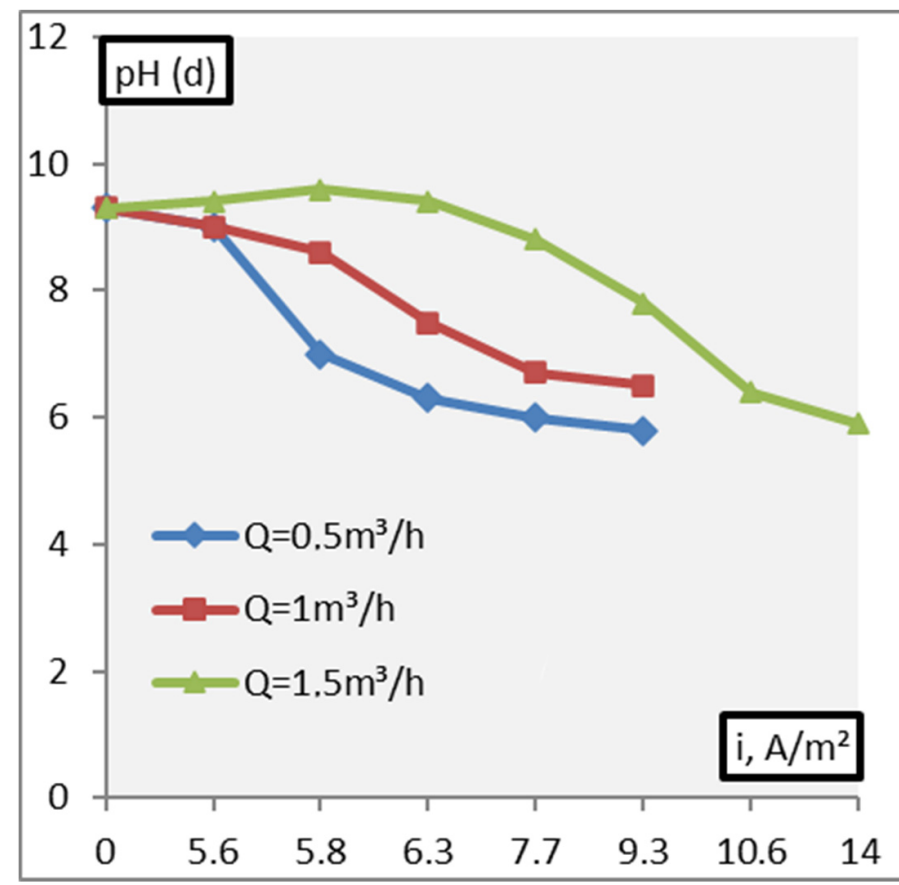

(a)

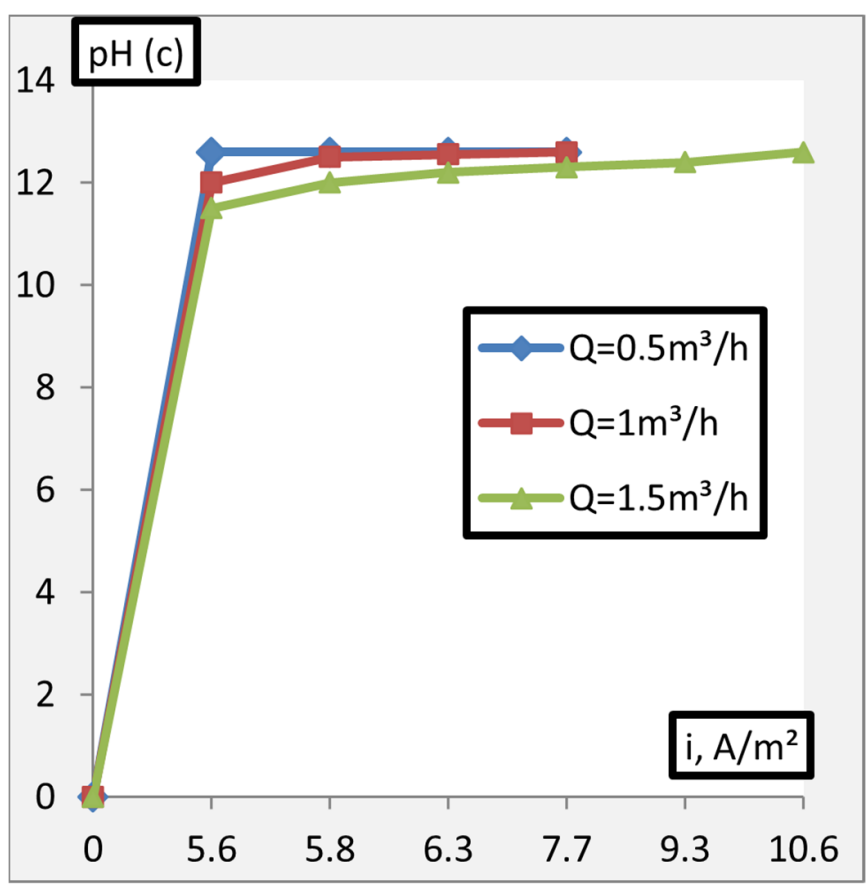

(b)

Figure 8. Dependence of the $\mathrm{pH} .((\mathbf{a})-\mathrm{pH}(\mathrm{d}),(\mathbf{b})-\mathrm{pH}(\mathrm{c}))$ adjustment of alkaline solutions on the current density and process performance (initial $\mathrm{pH}=9.3$ )

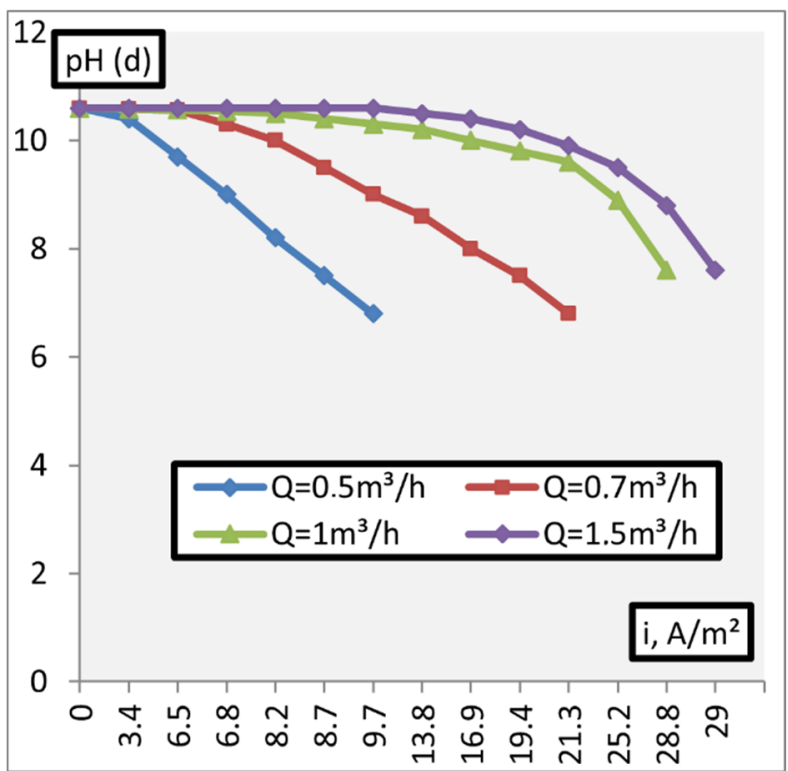

(a)

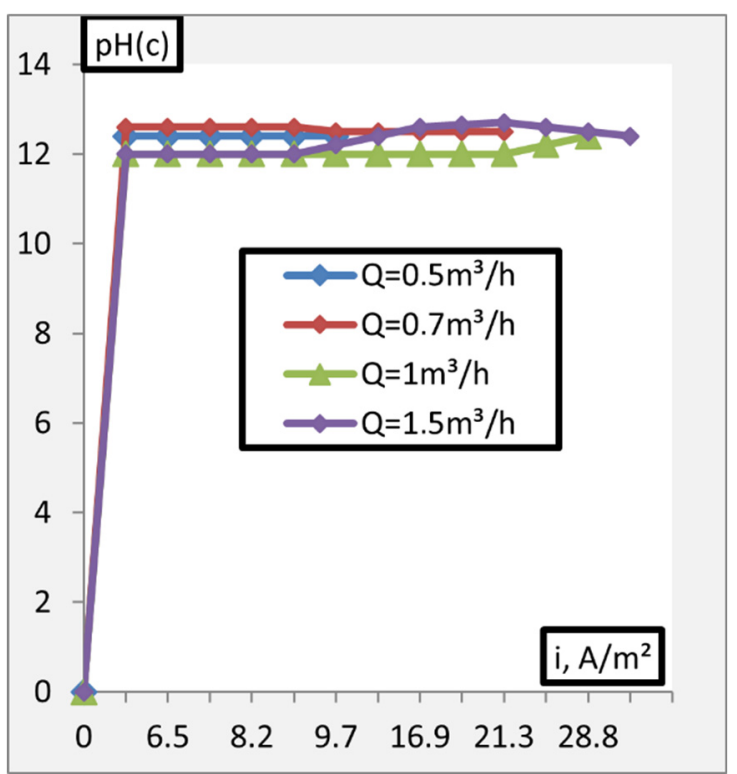

(b)

Figure 9. Dependence of the $\mathrm{pH} .((\mathbf{a})-\mathrm{pH}(\mathrm{d}),(\mathbf{b})-\mathrm{pH}(\mathrm{c}))$ adjustment of alkaline solutions on the current density and process performance (initial $\mathrm{pH}=10.6$ ). 


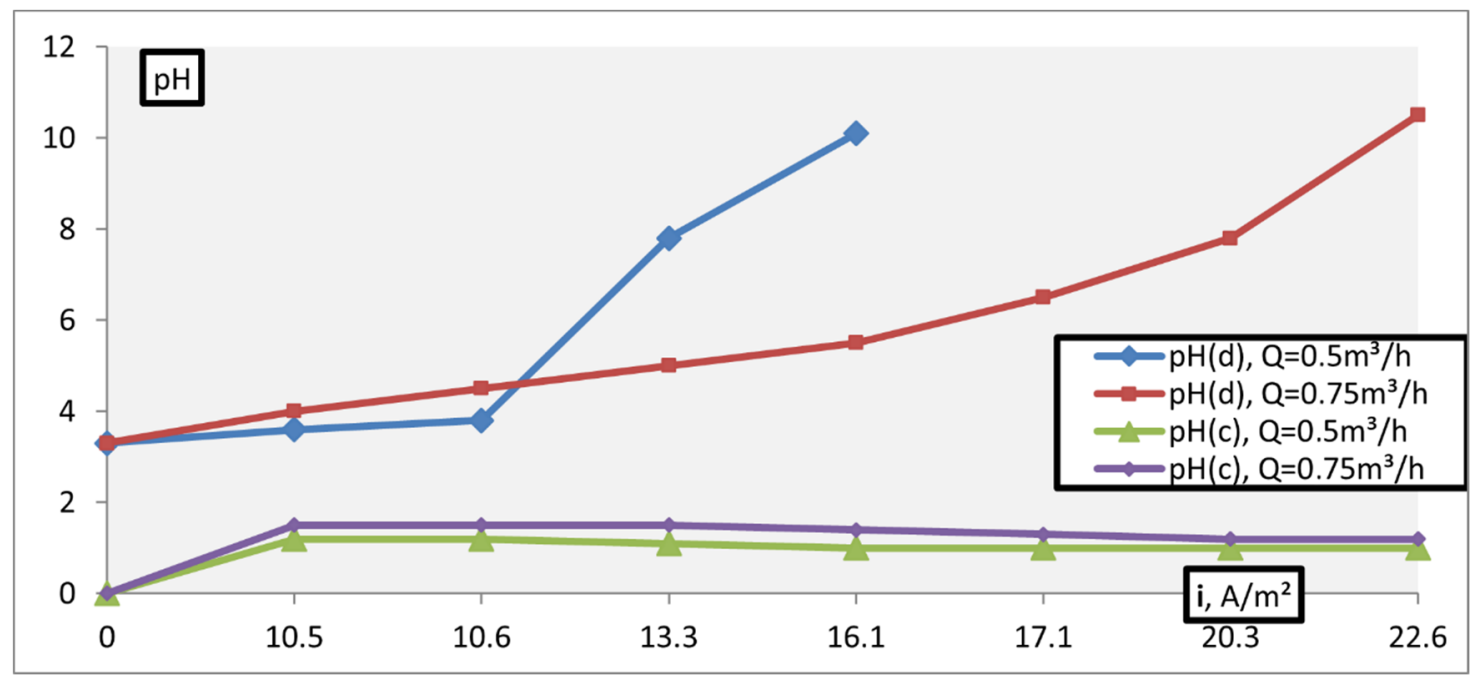

Figure 10. $\mathrm{pH}$ adjustment of acidic solutions $(\mathrm{pH}=3.3)$.

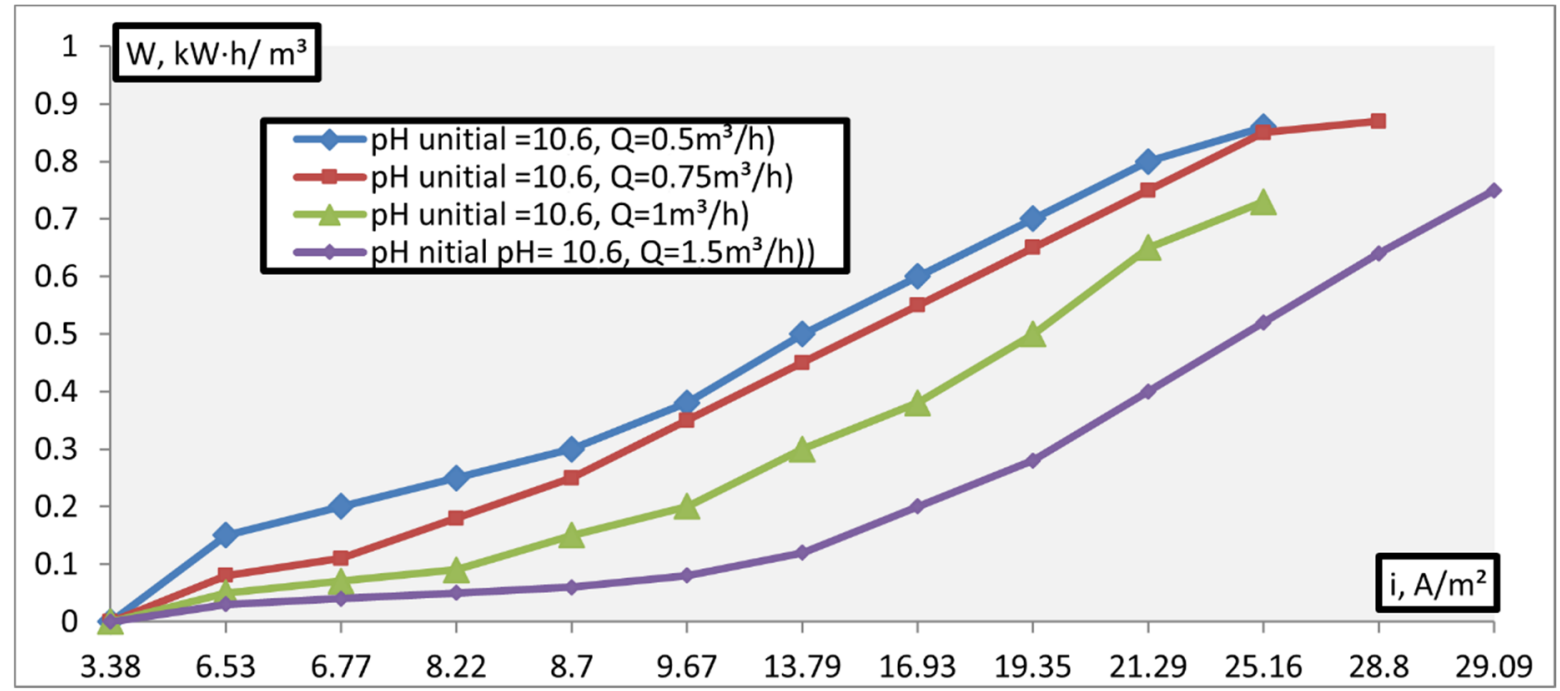

Figure 11. Dependence of the energy consumption of the process of adjusting acidic solutions on the current density.

Figure 7 shows the dependence of the $\mathrm{pH}$ adjustment of alkaline solutions on the current density. The membrane package is assembled from MK-40 and MB-2.

The analysis of the study results showed that the neutralization of weakly alkaline solutions ( $\mathrm{pH}=7.5-8.5)$ can be achieved under conditions of current density values $\left(\mathrm{i} \approx 1 \mathrm{~A} / \mathrm{m}^{2}\right)$. Further current density increase leads to a shift of $\mathrm{pH}$ in the solutions (dialysate) from a neutral ( $\mathrm{pH} 7$ ) to acidic environment. An increase in the alkalinity of the working solutions in the $\mathrm{pH}$ range of 8.5-11.0 requires a significant increase in the current density to neutralize these solutions: The greater the deviation of the $\mathrm{pH}$ value of the initial solution from neutral, the higher the voltage should be.

Figures 8 and 9 show the results of $\mathrm{pH}$ adjusting of solutions with an initial value of $\mathrm{pH}=9.3$ and $\mathrm{pH}=10.6$, respectively, with different operating capacities of the apparatus. It was found that in conditions of constant productivity, an increase in current density increases the intensity of $\mathrm{pH}$ decreasing, and an increase in productivity increases the value of current density required to neutralize the solution. Besides, the intensity of lowering the $\mathrm{pH}$ of the solution is greater, the higher the current density; and it is less, the greater the productivity of the apparatus.

During electrodialysis of the initial solution with $\mathrm{pH}>11$, a decrease in the $\mathrm{pH}$ of the product (dialysate) was practically not achieved. This is probably due to the operation of 
the installation under conditions above the limiting current value, when the splitting of water molecules occurs at the interface between the monopolar membrane and the solution.

Under the operating conditions of the installation up to the limiting current value when using only cation-exchange and bipolar membranes, acid is formed in the dialysate chamber due to $\mathrm{H}^{+}$ions generated by the bipolar membrane and chlorine ions of the working solution, and the acidity of alkaline solutions decreases. Under extreme conditions, at the interface between the cation exchange membrane and the solution, water molecules are split into $\mathrm{H}^{+}$and $\mathrm{OH}^{-}$ions. $\mathrm{H}^{+}$ions are transported by the cation exchange membrane, and the resulting $\mathrm{OH}$ - ions neutralize the $\mathrm{H}^{+}$ions generated by the bipolar membrane. As a result of this process, the acidity of the working solution does not decrease [42].

During the experiment on alkaline salt solutions, in the concentration sections of the apparatus, in contrast to dialysate chambers, the formation of a 5-6\% sodium hydroxide solution, with a volume of no more than $2 \%$ of the product volume, took place.

In addition to alkaline solutions, the possibility of adjusting the $\mathrm{pH}$ of acidic saline solutions was studied. To solve this problem, the electrodialysis apparatus was equipped with bipolar- and anion-exchange membranes.

Correction of the acidity of sodium chloride solutions with $\mathrm{pH}=2.7$ and $\mathrm{pH}=3.3$ was carried out. The initial solution was supplied only to the dialysate chambers of the apparatus.

In these chambers, when voltage is applied, sodium hydroxide is formed due to $\mathrm{Na}^{+}$ cations of the work solution and $\mathrm{OH}^{-}$anions, generated by the bipolar membrane. As a result of the experiment, it was found that when processing a solution with $\mathrm{pH}=2.7$ even at a high current density $\left(\mathrm{i}>20 \mathrm{~A} / \mathrm{m}^{2}\right)$, the $\mathrm{pH}$ of the product does not change, which is probably due to the neutralization of hydroxyl ions generated by the bipolar membrane by hydrogen ions obtained by splitting water at the border of a monopolar membrane with a solution under extreme operating conditions of the device.

The results obtained during the electrodialysis treatment of an acidic initial (working) solution with $\mathrm{pH}>3.3$ are shown in Figure 10.

As follows from the data obtained, the intensity of change in the acidity of the solution depends on the current density and apparatus process performance: With an increase in the value of these indicators, the $\mathrm{pH}$ of the product increases and, consequently, the energy consumption of the process increases. Figure 11 presents data on dependence of the energy consumption of the process of adjusting acidic solutions on the current density.

\section{Conclusions}

The reagent-free process of $\mathrm{pH}$ correction of $\mathrm{NaCl}$ solutions of different acidities was carried out by the method of bipolar electrodialysis.

It was found that in the range $3.0 \leq \mathrm{pH} \leq 11.0$, the change in the acidity of the working solution to a neutral value depends on the initial $\mathrm{pH}$ value, current density and the performance of the apparatus.

It was found that the greater the deviation of the $\mathrm{pH}$ of the initial solution from the neutral value and the higher the productivity of the installation, the higher the current density and energy consumption for the neutralization process should be. It has been established that when the apparatus is operating in the overcurrent mode, bipolar electrodialysis is ineffective for correcting the $\mathrm{pH}$ of solutions, since the $\mathrm{H}^{+}$and $\mathrm{OH}^{-}$ions generated by the bipolar membrane are neutralized by the corresponding ions that are formed at the interface between the monopolar membrane and the solution during water dissociation. The data obtained in this work can be used to simulate the processes of $\mathrm{pH}$ correction in solutions. The proposed technology for $\mathrm{pH}$ correction can find application in the regeneration of water used to feed steam circuits of steam boilers, in the processing of natural water, juice and wine, or in the production of ultrapure water. etc. The development of reagent-free methods for the acidification and decarbonization of natural waters and carbonate-containing technological solutions is a very urgent task. Its solution would make it possible to harmonize the stages of pretreatment and desalination and ensure 
reagent-free and ecological cleanliness of the entire technological process. In our opinion, the development of methods for adjusting the $\mathrm{pH}$ of natural waters and technological solutions before their desalination and deionization is more in demand.

Author Contributions: Conceptualization, I.B. and T.K.; methodology, I.B. and T.K.; software, I.B.; validation, I.B., T.K., and V.P.; formal analysis, V.P.; investigation, N.N.; resources, I.B.; data curation, I.B.; writing—original draft preparation, I.B. and T.K.; writing—review and editing, I.B., T.K., A.P. and O.P.; visualization, A.P.; supervision, V.P.; project administration, O.P. and N.I. All authors have read and agreed to the published version of the manuscript.

Funding: This research received no external funding.

Institutional Review Board Statement: Not applicable.

Informed Consent Statement: Informed consent was obtained from all subjects in-volved in the study.

Data Availability Statement: Not applicable.

Conflicts of Interest: The authors declare no conflict of interest.

\section{References}

1. Frenkel, V. Membrane technologies: Past, present and future (on the example of North America). Water Supply Sanit. Eng. 2010, 8 , 48-54.

2. Lobovko, A. Ways of solving the problem of regulation of acidity of technological liquids. Young Sci. 2018, 44, 19-22.

3. Laptev, A.; Sergeeva, E. Water treatment and water purification in the energy sector. Part 1. Water: Chemistry and Ecology 2011, 3 , 33-40.

4. Bejanidze, I.; Pohrebennyk, V.; Kharebava, T.; Koncelidze, L.; Jun, C. Correction of the chemical composition of the washing waters received as a result of $\mathrm{pH}$ cation exchange of ionex change resin. In Proceedings of the International International Multidisciplinary Scientific GeoConference SGEM, Albena, Bulgaria, 30 June-6 July 2019; pp. 133-140.

5. Zabolotskiy, V.I.; Utin, S.V.; Sheldeshov, N.V.; Lebedev, K.A.; Vasilenko, P.A. Reseach of the process of pH correction of diluted electrolyte solutions by electrodialysis with bipolar membranes. Electochemystry 2011, 47, 343-348.

6. Bejanidze, I.; Petrov, O.; Pohrebennyk, V.; Kharebava, T.; Nakashidze, N.; Davitadze, N.D.; Petrov, A. Sorption of organic electrolytes and surfactants from natural waters by heterogeneous membranes. Appl. Sci. 2020, 10, 7383. [CrossRef]

7. Strathmann, H. Ion-Exchange Membrane Separation Processes, 1st ed.; Elsevier: Amsterdam, The Netherlands, 2004; ISBN 044450236X.

8. Petrov, O.; Petrichenko, S.; Yushchishina, A.; Mitryasova, O.; Pohrebennyk, V. Electrospark method in galvanic wastewater treatment for heavy metal removal. Appl. Sci. 2020, 10, 5148.

9. Strathmann, H. Electrodialysis, a mature technology with a multitude of new applications. Desalination 2010, 264, 268-288. [CrossRef]

10. Przystupa, K.; Petrichenko, S.; Yushchishina, A.; Mitryasova, O.; Pohrebennyk, V.; Kochan, O. Electric spark method of purification of galvanic waste waters. Przeglad Elektrotechniczny 2020, 12, 230-233.

11. Sajjad, A.-A.; Yunus, M.Y.B.M.; Azoddein, A.A.M.; Hassell, D.G.; Dakhil, I.H.; Hasan, H.A. Electrodialysis Desalination for Water and Wastewater: A Review. Chem. Eng. J. 2020, 380, 122231.

12. Bejanidze, I. Save natural-save your life. Ga. Natl. Sci. Acad. Bull. 2010, 36, 76-84.

13. Ezugbe, E.O.; Rathilal, S. Membrane Technologies in Wastewater Treatment: A Review. Membranes 2020, 10, 89. [CrossRef]

14. Gurreri, L.; Tamburini, A.; Cipollina, A.; Micale, G. Electrodialysis Applications in Wastewater Treatment for Environmental Protection and Resources Recovery: A Systematic Review on Progress and Perspectives. Membranes 2020, 10, 146. [CrossRef]

15. Niftaliev, S.; Kozaderova, O.; Kim, K.; Velho, F. The use of electrodialysis to obtain acid and alkali from a concentrated solution of sodium sulfate. Bull. VGUIT 2014, 4, 175-178. (In Russian)

16. Zhao, W.Y.; Zhou, M.; Yan, B.; Sun, X.; Liu, Y.; Wang, Y.; Xu, T.; Zhang, Y. Waste conversion and resource recovery from wastewater by ion exchange membranes: State-of-the-art and perspective. Ind. Eng. Chem. Res. 2018, 57, 6025-6039. [CrossRef]

17. Xu, T.; Huang, C. Electrodialysis-Based separation technologies: A critical review. AiCHE J. 2008, 54, 3147-3159. [CrossRef]

18. $\mathrm{Xu}, \mathrm{T}$. Ion exchange membranes: State of their development and perspective. J. Membr. Sci. 2005, 263, 1-29. [CrossRef]

19. Nagarale, R.K.; Gohil, G.S.; Shahi, V.K. Recent developments on ion-exchange membranes and electro-membrane processes. Adv. Colloid Interface Sci. 2006, 119, 97-130. [CrossRef]

20. Basile, A.; Cassano, A.; Rastogi, N. Advances in Membrane Technologies for Water Treatment. Materials, Processes and Applications; Woodhead Publishing: Cambridge, UK, 2015; 666p, ISBN 9781782421214.

21. Tanaka, Y. Ion Exchange Membranes: Fundamentals and Applications; Elsevier: Amsterdam, The Netherlands, 2007; Volume 12, ISBN 0927-5193.

22. Ran, J.; Wu, L.; He, Y.; Yang, Z.; Wang, Y.; Jiang, C.; Ge, L.; Bakangura, E.; Xu, T. Ion exchange membranes: New developments and applications. J. Membr. Sci. 2017, 522, 267-291. [CrossRef] 
23. Pal, P. Membrane-Based Technologies for Environmental Pollution Control; Butterworth-Heinemann: Oxford, UK, 2020; 784p, ISBN 9780128194553.

24. Nikonenko, V.; Pismenskaya, N.; Belova, E.; Sistat, P.; Huguet, P.; Pourcelly, G.; Larchet, I. Intensive current transfer in membrane systems: Modelling, mechanisms and application in electrodialysis. Adv. Colloid Interface Sci. 2010, 160, 101-123. [CrossRef]

25. Bejanidze, I.; Kharebava, T.; Davitadze, N.; Kontselidze, Z.; Kontselidze, L. Purification of Natural and Wastewater by Electromembrane Technology: Monograph; Series Membrane Technology; Shota Rustaveli State University: Batumi, Georgia, 2019 ; p. 178. (In Georgian)

26. Campione, A.; Gurreri, L.; Ciofalo, M.; Micale, G.; Tamburini, A.; Cipollina, A. Electrodialysis for water desalination: A critical assessment of recent developments on process fundamentals, models and applications. Desalination 2018, 434, 121-160. [CrossRef]

27. Bobylev, V.P.; Matukhno, Y.V.; Turishchev, V.V.; Belokon, K.V. Methodical approach for selection of design parameters of electrodialisys diaphragmless apparatus for regeneration of electrolytecontaining solution. Metall. Min. Ind. $2013,2,77$.

28. Singh, R.; Hankins, N. Emerging Membrane Technology for Sustainable Water Treatment; Elsevier Science: Amsterdam, The Netherlands, 2016; 480p, ISBN 9780444633125.

29. Bernardes, A.M.; Ferreira, J.Z.; Rodrigues, M.S. Electrodialysis and Water Reuse: Novel Approaches; Springer: Berlin/Heidelberg, Germany, 2014; ISBN 9783642402494.

30. Bejanidze, I.; Kharebava, T.; Pohrebennyk, V.; Didmanidze, N.; Davitadze, N. The study of composition and physical and chemical properties of some natural waters of Georgia. In Water Supply and Wastewater Disposal. Designing, Construction, Operation and Monitoring: Monograph; Politechnika Lubelska: Lublin, Poland, 2020; pp. 8-23, ISBN 978837947409.

31. Bejanidze, I.; Petrov, O.; Kharebava, T.; Pohrebennyk, V.; Davitadze, N.; Didmanidze, N. Study of the healing properties of natural sources of Georgia and modeling of their purification processes. Appl. Sci. 2020, 10, 6529. [CrossRef]

32. Merkel, A.; Ashrafi, M.; Ecer, J. Bipolar membrane electrodialysis assisted pH correction of milk whey. J. Membr. Sci. 2018, 555, 185-196. [CrossRef]

33. Scarazzato, T.; Panossian, Z.; Tenório, J.A.S.; Pérez-Herranz, V.; Espinosa, D.C.R. A review of cleaner production in electroplating industries using electrodialysis. J. Clean. Prod. 2017, 168, 1590-1602. [CrossRef]

34. Pawlowski, S.; Crespo, J.; Velizarov, S. Profiled Ion Exchange Membranes: A Comprehensible Review. Int. J. Mol. Sci. 2019, 20, 165. [CrossRef]

35. Mareev, S.A.; Evdochenko, E.; Wessling, M.; Kozaderova, O.A.; Niftaliev, S.I.; Pismenskaya, N.D.; Nikonenko, V.V. A comprehensive mathematical model of water splitting in bipolar membranes: Impact of the spatial distribution of fixed charges and catalyst at bipolar junction. J. Membr. Sci. 2020, 603, 118010. [CrossRef]

36. Bejanidze, I.; Kharebava, T.; Koncelidze, Z. The use of bipolar electrodialysis for processing juice production waste. Sci. Rev. 2018, 2, 35-38.

37. Nikonenko, V.; Urtenov, M.; Mareev, S. Pourcelly Mathematical Modeling of the Effect of Water Splitting on Ion Transfer in the Depleted Diffusion Layer Near an Ion-Exchange Membrane. Membranes 2020, 10, 22. [CrossRef]

38. Donskikh, A.N. A Method for Regulating the Acidity of Whey in the Process of Electrodialysis. Russian Patent No. 2515096, 5 October 2014. Bul. No. 13.

39. Kamcev, J.; Sujanani, R.; Jang, E.S.; Yan, N.; Moe, N.; Paul, D.R.; Freeman, B.D. Salt concentration dependence of ionic conductivity in ion exchange membranes. J. Membr. Sci. 2018, 547, 123-133. [CrossRef]

40. Veerman, J. The Effect of the NaCl Bulk Concentration on the Resistance of Ion Exchange Membranes-Measuring and Modeling. Energies 2020, 13, 1946. [CrossRef]

41. Kamcev, J.; Doherty, C.M.; Lopez, K.P.; Hill, A.J.; Paul, D.R.; Freeman, B.D. Effect of fixed charge group concentration on salt permeability and diffusion coefficients in ion exchange membranes. J. Membr. Sci. 2018, 566, 307-316. [CrossRef]

42. La Cerva, M.; Gurreri, L.; Tedesco, M.; Cipollina, A.; Ciofalo, M.; Tamburini, A.; Micale, G. Determination of limiting current density and current efficiency in electrodialysis units. Desalination 2018, 445, 138-148. [CrossRef] 